\title{
Corrigendum: Making brain-machine interfaces robust to future neural variability
}

\author{
David Sussillo, Sergey D. Stavisky, Jonathan C. Kao, Stephen I. Ryu \& Krishna V. Shenoy
}

Nature Communications 7:13749 doi: 10.1038/ncomms13749 (2016); Published 13 Dec 2016; Updated 20 Jan 2017

The financial support for this Article was not fully acknowledged. The Acknowledgements should have included the following:

This work was supported by the National Science Foundation Graduate Research Fellowship (J.C.K., S.D.S.); NSF IGERT 0734683 (S.D.S.); Christopher and Dana Reeve Paralysis Foundation (S.I.R. and K.V.S.); and the following to K.V.S.: Burroughs Welcome Fund Career Awards in the Biomedical Sciences, Defense Advanced Research Projects Agency Reorganization and Plasticity to Accelerate Injury Recovery N66001-10-C-2010, US National Institutes of Health Institute of Neurological Disorders and Stroke Transformative Research Award R01NS076460, US National Institutes of Health Director's Pioneer Award 8DP1HD075623-04, US National Institutes of Health Director's Transformative Research Award (TR01) from the NIMH \#5R01MH09964703, and Defense Advanced Research Projects Agency NeuroFAST award from BTO \#W911NF-14-2-0013.

This work is licensed under a Creative Commons Attribution 4.0 International License. The images or other third party material in this article are included in the article's Creative Commons license, unless indicated otherwise in the credit line; if the material is not included under the Creative Commons license, users will need to obtain permission from the license holder to reproduce the material. To view a copy of this license, visit http://creativecommons.org/licenses/by/4.0/
}

(C) The Author(s) 2017 